\title{
Natural Killer Cell Cytotoxicity and Immunosuppressive Cytokines (IL-10, TGF- $\beta 1$ ) in Patients with Gastric Cancer
}

\author{
Andrzej Szkaradkiewicz, ${ }^{1}$ Tomasz M. Karpiński, ${ }^{1}$ Michał Drews, ${ }^{2}$ Maciej Borejsza-Wysocki, \\ Przemysław Majewski, ${ }^{3}$ and Ewa Andrzejewska ${ }^{1}$ \\ ${ }^{1}$ Department of Medical Microbiology, University of Medical Sciences in Poznań, Wieniawskiego 3 Street, 61-712 Poznań, Poland \\ ${ }^{2}$ Department of General, Gastroenterological and Endocrinological Surgery, University of Medical Sciences in Poznan, \\ Przybyszewskiego 49 Street, 60-355 Poznań, Poland \\ ${ }^{3}$ Department of Clinical Pathomorphology, University of Medical Sciences in Poznań, Przybyszewskiego 49 Street, \\ 60-355 Poznań, Poland
}

Correspondence should be addressed to Andrzej Szkaradkiewicz, szkaradkiewicza@poczta.onet.pl

Received 18 August 2009; Accepted 16 February 2010

Academic Editor: Manoor Prakash Hande

Copyright () 2010 Andrzej Szkaradkiewicz et al. This is an open access article distributed under the Creative Commons Attribution License, which permits unrestricted use, distribution, and reproduction in any medium, provided the original work is properly cited.

\begin{abstract}
Cytotoxic activity of NK cells was estimated as related to IL-10 and TGF- $\beta 1$ serum levels and Helicobacter pylori infection in gastric cancer patients. Moreover, we sought to determine whether human gastric adenocarcinoma cells in vitro release IL-10, TGF- $\beta 1$ or factor(s) affecting NK cytotoxicity. The studies were conducted on 42 patients with gastric cancer (14 with I-II stage-group 1; 28 with III-IV stage-group 2) and on 20 healthy volunteers. The cytotoxicity was tested on NK cells isolated from peripheral blood. IL-10 and TGF- $\beta 1$ levels were determined by ELISA. H. pylori was detected in cultures of gastric mucosa biopsies and in direct preparations. In $71.4 \%$ patients of group 1 NK cytotoxicity and IL-10 serum levels remained within a normal range while in $68 \%$ patients of group 2 a marked decrease was noted in cytotoxic function of NK cells, accompanied by increased levels of IL-10 in serum. In turn, in most patients of either group, independently of NK cytotoxicity and stage grouping in the patients, elevated serum levels of TGF- $\beta 1$ were detected. Presence of $H$. pylori infection manifested no relationship with NK cytotoxicity, IL-10, or the TGF- $\beta 1$ serum levels. In cultures of tumour cells presence of IL-10 and TGF- $\beta 1$ was demonstrated. Nevertheless, supernatants of the cultures did not change cytotoxic activity of NK cells. Development of gastric carcinoma is accompanied by markedly decreased cytotoxic function of NK cells and by elevated IL-10 and TGF- $\beta 1$ serum levels. Gastric carcinoma cells may release IL-10, the suppressive activity of which may in a secondary manner decrease NK cytotoxicity.
\end{abstract}

\section{Introduction}

Natural killer (NK) cells account for $3 \%-5 \%$ of human peripheral blood lymphocytes, playing an important role in host innate immunity, mediating cytotoxicity toward tumours or pathogen-infected cells $[1,2]$. In studies performed till now on NK cell activity in gastric cancer patients a decrease was demonstrated in their antitumor functions, which followed tumour progression [3]. In turn, interleukin10 (IL-10) represents an immunoregulatory cytokine with potent anti-inflammatory and immunosuppresive activities, but exerting also stimulatory effects on NK cells $[4,5]$.
Another cytokine that mediates suppression of immune response as well as strong inhibition of epithelial-cell growth involves the transforming growth factor- $\beta$ (TGF- $\beta$ ), produced in humans in 3 highly homologous isoforms (TGF- $\beta 1$, TGF- $\beta 2$, TGF- $\beta 3$ ), with TGF- $\beta 1$ being the most prevalent in the circulating blood $[6,7]$.

Increased serum levels of IL-10 and TGF- $\beta 1$ were described in an advanced gastric cancer $[8,9]$. In parallel, the link was demonstrated between bacterial infection with Helicobacter pylori and gastric cancer $[10,11]$.

Studies in vitro show that $H$. pylori strongly activates NK cells [12]. However, no data are till now available on 
interrelationship of NK cell cytotoxicity and circulating IL-10 levels, in relation to $H$. pylori infection in gastric cancer patients.

The present study was conducted to determine whether NK cell cytotoxicity remains related to serum IL-10 and TGF$\beta 1$ levels and $H$. pylori infection in gastric cancer patients. Furthermore, we sought to determine whether human gastric adenocarcinoma cell line (AGS) in vitro releases IL10 , TGF- $\beta 1$, or factor(s) directly affecting cytotoxicity of NK cells originating from healthy individuals.

\section{Materials and Methods}

2.1. Patients. The studies were conducted on 42 adult patients with histologically confirmed diagnosis of gastric adenocarcinoma. Using stage grouping according to WHO classification of gastric tumours [13], two groups of the patients were distinguished. Group 1 included 14 patients (10 males and 4 females), $54 \pm 6.2$ years of age. In all individuals of the group tumour stage of I-II was diagnosed. The second group consisted of 28 patients (22 males and 6 females), $61 \pm 7.2$ years of age. In all patients of the group stage IIIIV of the disease was disclosed.

The control group included 20 adult healthy volunteers (12 males and 8 females), $56 \pm 8.0$ years of age, that is, individuals who matched the groups of patients in age and sex.

The material for studies involved samples of peripheral blood and biopsies of gastric mucosa, obtained during gastroscopy 2 weeks before surgical treatment.

All the research protocols were reviewed and approved by the Ethics Committee by the University of Medical Sciences in Poznań, Poland.

2.2. H. Pylori Detection. Biopsies of gastric mucosa were plated on Columbia agar (bioMerieux) with 7\% sheep blood with antibiotic supplement (Helicobacter pylori Selective Supplement Dent, Oxoid). The incubation was conducted in microaerophilic conditions (Genbox microaer, bioMerieux) at $37^{\circ} \mathrm{C}$ for 4 to 10 days. The isolated Helicobacter pylori strains were identified on the basis of Gram staining as well as by production of urease, catalase, and oxidase.

Moreover, the presence of $H$. pylori was identified in the tissue sections stained with Giemsa.

2.3. Isolation of NK Cells. Peripheral blood mononuclear cells (PBMCs) were isolated from heparinized blood by centrifugation in the Ficoll/Isopaque density gradient (specific density $1.078 \mathrm{~g} / \mathrm{cm}^{3}$, Pharmacia) for 20 minutes at $400 \mathrm{~g}$. The interface cells were washed twice in PBS, scored and suspended in PBS, and enriched with $2 \%$ foetal calf serum (FCS; Gibco), at $10^{7} \mathrm{PBMC} / \mathrm{mL}$. NK cells were isolated by the biomagnetic technique via negative selection using EasySep Human NK cell Enrichment Kit (StemCell Technologies). The isolated cells were washed twice and suspended at $10^{6}$ cells $/ \mathrm{mL}$ in RPMI 1640 enriched with $10 \%$ FCS, 2 mM L-glutamine (Sigma), and antibiotics. The obtained cell preparation contained $80 \%-85 \%$ NK cells (CD3 - CD16+/CD56+), as demonstrated by flow cytometry, using CD3-FITC/CD16+CD56-PE (Beckman Coulter). Cell viability was tested using $0.5 \%$ trypan blue (following every isolation the percentage of dead cells did not exceed $5 \%)$.

2.4. AGS Cell Line. Human gastric adenocarcinoma cell line (AGS) termed ATCC number: CRL-1739 was obtained from LGC Promochem. AGS cells were cultured in T-25 tissue-culture flasks (Nunc) in RPMI 1640, enriched with $10 \%$ FCS, $2 \mathrm{mM}$ L-glutamine (Sigma), and antibiotics at the temperature of $37^{\circ} \mathrm{C}$, in $5 \% \mathrm{CO}_{2}$ atmosphere. Before using AGS cells as targets in cytotoxicity assay, the cells were detached from bottom of the flasks and washed twice. Cell viability was tested using $0.5 \%$ trypan blue (the percentage of dead cells did not exceed 5\%).

2.5. Cytotoxicity Assay. NK cell cytotoxicity was determined with the Non-Radioactive Cytotoxicity Assay (CytoTox 96 Assay, Promega) using AGS cells as targets. Every examination involved 4 independent experiments. In every experiment, each well of 96-well microtitre plates (Nunc) was charged with one of the following cell cultures: $2 \times 10^{3}$ AGS (spontaneous release), $2 \times 10^{3}$ AGS (total lysis), $10^{4} \mathrm{NK}$ cells (spontaneous release), and $2 \times 10^{3}$ AGS with $10^{4}$ effector NK cells (experimental release). In preliminary experiments the effector to target cells ratio $5: 1(\mathrm{E} / \mathrm{T})$ was found to be sufficient to obtain maximum cytotoxicity of NK cells isolated from healthy volunteers. The plates were centrifuged at $50 \mathrm{~g}$ for 5 minutes and incubated at $37^{\circ} \mathrm{C}$ in $5 \% \mathrm{CO}_{2}$ for 4 hours. Subsequently, after centrifugation of the plates at $500 \mathrm{~g}$ for 5 minutes, 50 microliters of the supernatants were transferred from every well to a fresh 96-well plate and incubated with the CytoTox 96 Kit components, according to the manufacturer's protocol. The results were read using ELISA Reader 250 (bioMerieux) at $\lambda=490 \mathrm{~nm}$. Specific lysis was subsequently calculated from readouts of absorbance (A) in the following manner:

$\%$ cytotoxicity $=100 \% \times[\mathrm{A} \exp -\mathrm{A}$ spontaneous $($ AGS + NK) release]/(A total lysis - A spontaneous AGS release).

The spontaneous release involved lactate dehydrogenase (LDH) released from target cells or from effector cells incubated alone with the complete medium.

2.6. Studies on AGS Culture Supernatants. AGS cell line cultures were initiated at $10^{6}$ cells per $\mathrm{mL}$ and their supernatants were harvested after 24, 48, and 72 hours. At each time point the cell proliferation was estimated. In the obtained supernatants IL-10 levels were estimated. In parallel, the NK cells isolated from blood of healthy volunteers were cultured for 18 hours in RPMI 1640, enriched with 10\% FCS, $2 \mathrm{mM}$ L-glutamine (Sigma), and antibiotics at the temperature of $37^{\circ} \mathrm{C}$, in the atmosphere of $5 \% \mathrm{CO}_{2}$ in presence or absence of $10 \%$ of 48 -hour supernatants of AGS cultures. Then, the cells were washed twice and used for cytotoxicity assay. 
TABLE 1: NK cell cytotoxicity and immunosuppressive cytokines (IL-10, TGF- $\beta 1$ ) serum levels in healthy volunteers.

\begin{tabular}{lccr}
\hline No. of healthy volunteers & NK cell cytotoxicity $(\%)$ & $\begin{array}{c}\text { IL-10 (pg/mL) } \\
\text { mean } \pm \text { SD (range in parentheses) }\end{array}$ & TGF- $\beta 1$ (ng/mL) \\
\hline 20 & $52.6 \pm 7.38(44.0-68.0)$ & $1.55 \pm 1.1(1.0-3.0)$ & $18 \pm 3.34(13.5-24.0)$ \\
\hline
\end{tabular}

TABLE 2: NK cells cytotoxicity in patients with $H$. pylori-positive and $H$. pylori-negative gastric carcinomas.

\begin{tabular}{|c|c|c|c|c|}
\hline \multirow{2}{*}{ Examined group } & \multirow{2}{*}{ No. of patients } & \multicolumn{2}{|c|}{ No. (\%) of cases with NK cytotoxicity } & \multirow{2}{*}{$P$-value for difference } \\
\hline & & normal & decreased & \\
\hline $\begin{array}{l}\text { H. pylori-positive gastric } \\
\text { carcinomas }\end{array}$ & 15 & $7(46.7 \%)$ & $8(53.3 \%)$ & 1.0000 \\
\hline $\begin{array}{l}\text { H. pylori-negative gastric } \\
\text { carcinomas }\end{array}$ & 27 & $12(44.4 \%)$ & $15(55.6 \%)$ & \\
\hline
\end{tabular}

2.7. IL-10 Assay. IL-10 was estimated in serum using the immunoenzymatic technique (ELISA), employing the high sensitivity kits of Quantikine HS Human IL-10 Immunoassay (R\&D Systems), detecting on the average the IL-10 concentration of $0.5 \mathrm{pg} / \mathrm{mL}$. The absorbance was read at $\lambda=490 \mathrm{~nm}$ using the Reader 250 (bioMerieux). Every result represented a mean of three readouts from the established standard curve.

2.8. TGF- $\beta 1$ Assay. Total (active plus latent) TGF- $\beta 1$ was estimated in serum using the immunoenzymatic technique (ELISA), employing Quantikine TGF- $\beta 1$ Immunoassay kits (R\&D Systems), detecting on the average the TGF- $\beta 1$ concentration of $7.0 \mathrm{pg} / \mathrm{mL}$. The absorbance was read at $\lambda=450 \mathrm{~nm}$ using the Reader 250 (bioMerieux). Every result represented a mean of three readouts from the established standard curve.

2.9. Statistical Analysis. A correlation analysis between NK cell cytotoxicity and IL-10 or total TGF- $\beta 1$ serum levels was tested by computing Spearman's rank correlation coefficient $(r)$. The Mann-Whitney test was performed for analysis of the data related to effects of studied AGS culture supernatants on NK cell cytotoxicity. Differences in distributions of $H$. pylori results in studied patients were compared with Fisher's exact test. A $P$-value higher than .05 was considered nonsignificant.

\section{Results}

Results obtained in studies on NK cell cytotoxicity and serum levels of immunosuppressive cytokines (IL-10, TGF- $\beta 1$ ) in healthy volunteers are presented in Table 1 and Figures 1 and 2. The mean value of NK cell cytotoxicity was $52.6 \pm 7.38 \%$, while IL-10 serum level amounted, on the average, to $1.55 \pm$ $1.1 \mathrm{pg} / \mathrm{mL}$. In turn, total TGF- $\beta 1$ serum level amounted, on the average, to $18.0 \pm 3.34 \mathrm{ng} / \mathrm{mL}$. In further analysis, the lower cutoff value of the normal NK cell cytotoxicity was defined as $37.8 \%$ (i.e., at two SDs below mean normal value), the higher cutoff value of IL-10 serum level was set at $3.75 \mathrm{pg} / \mathrm{mL}$ (i.e., at two SDs above mean normal value), and

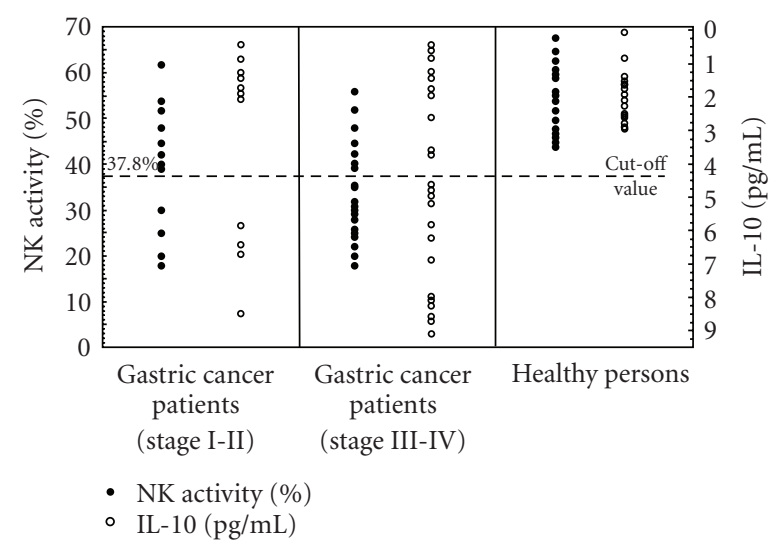

FIgURE 1: NK cells cytotoxic activity $(\bullet)$ and serum IL-10 levels ( $\circ$ ) in patients with gastric cancer and healthy volunteers. Gastric cancer patients were divided into two groups: group 1 with stages I-II and group 2 with stages III-IV.

the higher cutoff value of TGF- $\beta 1$ serum level was accepted to be $24.68 \mathrm{ng} / \mathrm{mL}$ (i.e., at two SDs above mean normal value).

Results obtained in studies on NK cell cytotoxicity, IL10 serum levels, and $H$. pylori infection in patients are presented in Figure 1 and Tables 2, 3, and 4. In group 1 with stage I-II gastric carcinoma, in 10 (71.4\%) patients, NK cell cytotoxicity and IL-10 serum levels remained within normal range. In parallel, in 4 of the patients presence of $H$. pylori infection was disclosed. On the other hand, in $4(28.6 \%)$ remaining patients a decrease was noted in NK cell cytotoxicity accompanied by an increase in IL-10 serum levels. In one of them presence of $H$. pylori infection was detected. In turn, in group 2 with stage III-IV gastric carcinoma, in $19(68 \%)$ patients, a reduction was noted in NK cell cytotoxicity, accompanied by an increase in IL-10 serum levels (except of 2 cases with the IL-10 level remaining within the normal range). In 7 of the patients presence of $H$. pylori infection was detected. On the other hand, in 9 (32.1\%) remaining patients NK cell cytotoxicity and IL-10 serum levels did not differ from those obtained in healthy volunteers. In three of them $H$. pylori infection was disclosed.

Analysis of NK cell cytotoxicity and IL-10 serum levels demonstrated a significant negative correlation between the 
TABLE 3: IL-10 serum levels in patients with $H$. pylori-positive and $H$. pylori-negative gastric carcinomas.

\begin{tabular}{lccc}
\hline Examined group & No. of patients & $\begin{array}{c}\text { No. }(\%) \text { of cases with IL-10 serum level } \\
\text { normal }\end{array}$ & increased \\
\hline $\begin{array}{l}\text { H. pylori-positive gastric } \\
\text { carcinomas }\end{array}$ & 15 & $7(46.7 \%)$ & $8(53.3 \%)$ \\
$\begin{array}{l}\text { H. pylori-negative gastric } \\
\text { carcinomas }\end{array}$ & 27 & $14(51.9 \%)$ & $13(48.1 \%)$ \\
\hline
\end{tabular}

TABLE 4: Number and proportion (\%) of studied cases with elevated serum levels of immunosuppressive cytokines (IL-10, TGF- $\beta 1$ ), as related to stage of gastric cancer.

\begin{tabular}{lccrr}
\hline \multirow{2}{*}{ Gastric cancer staging } & \multirow{2}{*}{ No. of patients } & \multicolumn{2}{c}{ No. (\%) of patients with elevated level of immunosuppressive cytokine } \\
& & IL-10 only & TGF- $\beta 1$ only & $7(50 \%)$ \\
\hline Stage I-II & 14 & $2(14.3 \%)$ & $11(39.3 \%)$ & IL10 + TGF- $\beta 1$ \\
Stage III-IV & 28 & $6(21.4 \%)$ & $(14.3 \%)$ \\
\hline
\end{tabular}

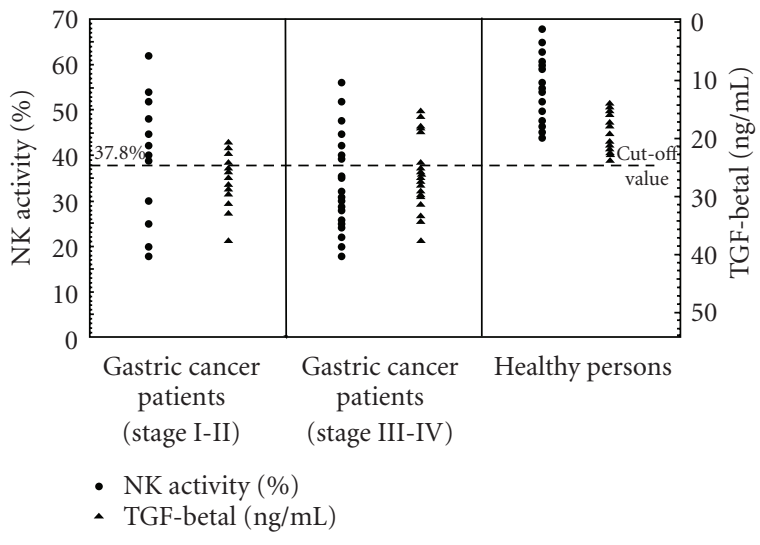

FIGURE 2: NK cells cytotoxic activity $(\bullet)$ and serum TGF- $\beta 1$ levels $(\boldsymbol{\Delta})$ in patients with gastric cancer and healthy volunteers. Gastric cancer patients were divided into two groups: group 1 with stages I-II and group 2 with stages III-IV.

variables both in group $1(r=-0.7398 ; P=.0025)$ and in group 2 of the patients $(r=-0.7675 ; P<.0001)$.

Results obtained in studies on NK cell cytotoxicity, TGF$\beta 1$ serum levels, and $H$. pylori infection in studied patients are presented in Figure 2 and Tables 4 and 5. In group 1 with stage I-II gastric carcinoma, in $9(64.3 \%)$ patients, an elevated level of serum TGF- $\beta 1$ was detected but in only two of them this was accompanied by elevation in serum levels of IL-10. In 3 of the patients presence of $H$. pylori infection was detected. In turn, in group 2 with stage III-IV gastric carcinoma, in $22(78,6 \%)$ patients, elevated serum levels of TGF- $\beta 1$ were detected, and in 11 of them this was associated with elevated serum levels of IL-10. In 8 of the patients presence of $H$. pylori infection was detected.

Analysis of NK cell cytotoxicity and TGF- $\beta 1$ serum levels failed to demonstrate a significant correlation between the variables both in group $1(r=-0.1488 ; P=.6116)$ and in group 2 of the patients $(r=0.3488 ; P=.0689)$.

In analysis of $H$. pylori infection sequels in gastric cancer patients, no significant relationships were disclosed with NK

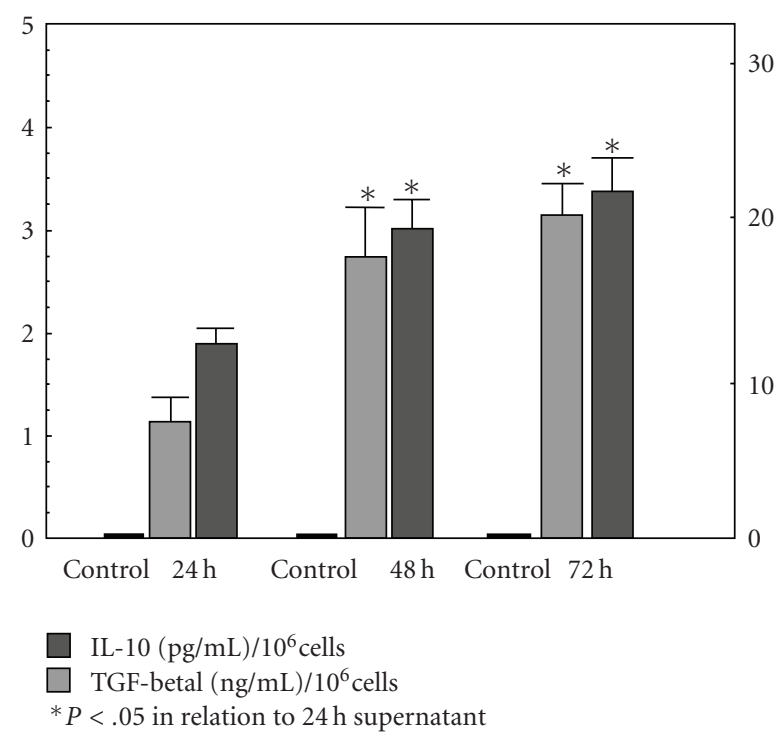

FIGURE 3: Quantitation of spontaneous release of immunosuppressive cytokines (IL-10, TGF- $\beta 1$ ) by human gastric adenocarcinoma cell line (AGS).

cell cytotoxicity, IL-10, or TGF- $\beta 1$ serum levels (Tables 2, 3, and 5).

In studies on spontaneous release of IL-10 and TGF$\beta 1$ by gastric adenocarcinoma (AGS) cell line, presence of the cytokine was detected in supernatants of the tumour cell cultures harvested after 24, 48, and 72 hours (Figure 3 ). Mean values of IL-10 levels in the above mentioned time points amounted to, respectively, $1.12 \pm 0.27 \mathrm{pg} / \mathrm{mL}, 2.8 \pm$ $0.5 \mathrm{pg} / \mathrm{mL}$, and $3.13 \pm 0.32 \mathrm{pg} / \mathrm{mL}$, and the cytokine levels noted after 48 and 72 hours were significantly higher than the level observed after 24 hours culture. Mean values of TGF- $\beta 1$ levels in the above mentioned time points amounted to, respectively, $12.65 \pm 0.92 \mathrm{ng} / \mathrm{mL}, 19.0 \pm 1.9 \mathrm{ng} / \mathrm{mL}$, and $21.6 \pm 2.19 \mathrm{ng} / \mathrm{mL}$, and the cytokine levels noted after 48 and 72 hours were significantly higher than the level observed after 24-hour culture. 
TABLE 5: TGF- $\beta 1$ serum levels in patients with $H$. pylori-positive and $H$. pylori-negative gastric carcinomas.

\begin{tabular}{|c|c|c|c|c|}
\hline \multirow{2}{*}{ Examined group } & \multirow{2}{*}{ No. of patients } & \multicolumn{2}{|c|}{ No. (\%) of cases with TGF- $\beta 1$ serum level } & \multirow{2}{*}{$P$-value for difference } \\
\hline & & normal & increased & \\
\hline $\begin{array}{l}\text { H. pylori-positive gastric } \\
\text { carcinomas }\end{array}$ & 15 & $4(26.7 \%)$ & $11(73.3 \%)$ & 1.0000 \\
\hline $\begin{array}{l}\text { H. pylori-negative gastric } \\
\text { carcinomas }\end{array}$ & 27 & $6(22.2 \%)$ & $21(77.8 \%)$ & \\
\hline
\end{tabular}

TABLE 6: Influence of 48 hours AGS culture supernatant on NK cells activity in healthy persons.

\begin{tabular}{lccc}
\hline $\begin{array}{l}\text { No. of healthy } \\
\text { volunteers }\end{array}$ & Tested supernatant & $\begin{array}{c}\text { NK activity (\%) mean } \pm \text { SD } \\
\text { (range in parentheses) }\end{array}$ & $P$-value for difference \\
\hline 16 & $48 \mathrm{~h} \mathrm{AGS} \mathrm{supernatant}$ & $43.81 \pm 4.65(38.0-55.0)$ & .087 \\
16 & PBS (control) & $50.56 \pm 7.19(40.0-61.0)$ & .087 \\
\hline
\end{tabular}

Results of studies on the effect of 48 hours supernatants from AGS cell line cultures on cytotoxicity of healthy volunteer' NK cells are presented in Table 6. The mean cytotoxicity of NK cells amounted to $43.8 \pm 4.65 \%$ and manifested no significant differences from the control values.

\section{Discussion}

In the conducted studies, NK cell cytotoxicity and immunosuppressive cytokines (IL-10, TGF- $\beta 1$ ) serum levels have shown variability related to the stage of gastric carcinoma. In most of the patients with stages I-II gastric cancer NK cell cytotoxicity and IL-10 serum levels have remained within normal values, in contrast to significantly elevated serum levels of TGF- $\beta 1$. On the other hand, in most patients with stages III-IV of the cancer NK cell cytotoxicity has been significantly lowered while serum IL-10 and TGF- $\beta 1$ levels have shown a significant increase, as compared to the control values. Therefore the presented studies on spontaneous cytotoxicity in patients with gastric cancer have been performed for the first time on NK (CD3- CD56+/CD16+) cells freshly isolated from peripheral blood. The obtained data may, in part, confirm and verify the earlier data on a decreased NK activity of peripheral blood lymphocytes in gastric cancer patients with tumour progression $[3,14]$.

In turn, the elevated level of circulating IL-10 in advanced gastric cancer was described already earlier $[8,15]$ but results of our studies, conducted in relation to NK cell cytotoxicity, allow to extend significance of the cytokine in the pathomechanism of tumour progression. The dual role of IL-10 was already well recognized [5]. On one hand, the cytokine exerts a direct suppressive effect on functions of monocytes/macrophages and on Th1 cell activity, strongly inhibiting production of macrophage inflammatory proteins, such as MIP- $2 \alpha$, IL- $1 \beta$, IL-6, IL- 8 , IL-12, IL18, TNF$\alpha$, and GM-CSF, and secretion of IFN- $\gamma$ and IL- 2 in T cells [4]. On the other hand, IL-10 has stimulatory effects on NK cells as well as cytotoxic T lymphocytes (CTLs) $[16,17]$. Moreover, the cytokine induces a population of regulatory cells $\left(\mathrm{T}_{\mathrm{Reg}}\right)$ which produce high levels of IL-10 and TGF- $\beta$ and can suppress the antigen-specific immune response [18].
Our studies, however, have demonstrated a negative correlation between NK cell cytotoxicity and IL-10 serum levels in patients with gastric cancer. Therefore, the elevated levels of IL-10 in advanced gastric cancer may inhibit production of IFN- $\gamma$, IL-2, IL-12, and IL-18, with the resulting restricted cytotoxic function of NK cells. The conclusion is backed up by results of Wen et al. [19], demonstrating a decreased activity of IFN- $\gamma$ and IL-2 especially in the advanced stages of gastric cancer. In addition, IL-2 is known to be significant for NK cell development and peripheral survival [20]. The cytokine also acts synergistically with both IFN- $\gamma$ and IL12, augmenting NK cell cytotoxicity [21]. In contrast to our results, the recently presented studies of Thong-Ngam et al. [22] demonstrated augmented IL-18 serum levels in gastric cancer. The cytokine, in combination with IL-10, can enhance NK cell cytotoxicity [16]. However, in the above quoted study the mean values of IL-18 serum level with standard deviation were given for an only generally defined cancer patient group. Therefore, it is difficult to relate the data to the results presented here, as related to pathological status of gastric cancer patients. As detected by us in some patients normal NK cell cytotoxicity may have been determined by elevated levels of circulating IL18 which, in combination with IL-10, upregulate NK cell function.

In this study, $H$. pylori infection has involved $36 \%$ of the patients while the obtained results related to NK cell cytotoxicity and IL-10 serum levels have not depended on infection with the pathogen. $H$. pylori infection has already been well documented to represent an important factor in pathogenesis of gastric cancer, inducing chronic gastric inflammation [11]. In parallel, it is postulated that promotion of gastric carcinogenesis includes also a significant role of $H$. pylori-stimulated high production of pro-inflammatory cytokines, mainly of IL-1, IL-6, IL-8, and TNF- $\alpha[23,24]$. In parallel, low levels of IL-10 multiply the risk of gastric cancer in patients infected with $H$. pylori [25]. Therefore, as demonstrated in the present study a decreased NK cell cytotoxicity and elevation of IL-10 serum levels seem to represent a sequel of neoplastic transformation and of tumour growth. In part, the conclusion may be backed up by observations that $H$. pylori disappears from 
the stomach with marked atrophic changes perhaps due to lack of nutrients for this pathogen [23]. Moreover, the in vitro experiments by Hafsi et al. [12] indicate that $H$. pylori may strongly activate NK cell, but fail to exert any direct effect on NK cell cytotoxicity. In parallel, Yun et al. [26] showed that $\mathrm{H}$. pylori and IL-12 act synergistically stimulating NK cells to high production of IFN- $\gamma$. Also, the authors suggested that the augmented secretion of the cytokine by NK cells induced activation of their cytotoxic function. Our results seem to contradict the suggestion, documenting impoverished cytotoxic activity of NK cells in patients in the course of gastric cancer. Nevertheless, the contradiction may be explained by data which point to phenotypic and functional differentiation of NK cells, IFN$\gamma$-producing CD56 ${ }^{\text {bright }}$ subset and the manifesting more cytotoxic activity CD56 ${ }^{\mathrm{dim}} \mathrm{NK}$ cells $[27,28]$. In this context, the augmented secretion of IFN- $\gamma$ by NK cells does not seem to determine the cytotoxic activity which we have estimated.

The elevated serum levels of IL-10, in turn, can hardly be explained exclusively by a shift towards a Th 2 immunological response, which accompanies development of gastric cancer, as described by Ren et al. [29]. In our studies the elevated serum levels of IL-10 most frequently have accompanied an advanced gastric cancer. In such a context, the main source of IL-10 seems to involve the tumour itself. The suggestion may be confirmed by our studies, documenting for the first time in vitro spontaneous release of IL-10 by AGS cell line. However, we have detected the effect of 48hour supernatants from cultures of the cells on NK cell cytotoxicity. Documenting the absence of a direct effect of tumour-released IL-10 on cytotoxic activity of NK cells, the observations remain in line with other results of our studies, pointing to the potential for indirect effects on the function of NK cells.

In turn, estimations of TGF- $\beta 1$ have shown a significantly elevated level of the cytokine in sera of most patients with either stages I-II or III-IV of gastric carcinoma. The data are consistent with results of Vagenas et al. [30] and have demonstrated no relationships between high levels of circulating TGF- $\beta 1$, tumors stage, and NK cell cytotoxicity. However, the observed elevated TGF- $\beta 1$ serum levels, which accompany gastric cancer, prove that the cytokine is involved in pathogenesis of the disease and may provide a diagnostic marker of tumour development. In parallel, in this study the elevated serum levels of TGF- $\beta 1$ in patients with gastric carcinoma have been found to be not related to presence of $H$. pylori infection. TGF- $\beta 1$ was convincingly shown to inhibit activity of NK cells [6]. Nevertheless, results of this study allow to conclude that the decreased cytotoxicity of peripheral blood NK cells has not been determined by overproduction of TGF- $\beta 1$. The conclusion is backed up by the data pointing to presence of the cytokine in blood circulation in an inactive, latent form, as a latency-associated protein [31].

In turn, the elevated serum levels of TGF- $\beta 1$ in the patients, independently of the gastric carcinoma stage, can hardly be explained by secretion of the cytokine by tumour cells only. Thus, the obtained results may corroborate the earlier data presented by Wakefield et al. [32] that production of TGF- $\beta 1$ by the tumor cells does not contribute significantly to the total TGF- $\beta 1$ in the blood circulation. The source of an elevated serum level of TGF- $\beta 1$ in the course of gastric carcinoma has remained incompletely clarified.

In conclusion, our current studies indicate that development of gastric cancer is accompanied by a marked decrease in cytotoxic activity of NK cells and by augmented levels of serum IL-10 and TGF- $\beta 1$. Manifestation of the disturbances is not dependent on $H$. pylori infection. Moreover, data obtained in this study indicate that gastric adenocarcinoma cells may release IL- 10 and TGF- $\beta 1$. The decreased cytotoxic function of NK cells seems to be determined mainly in a secondary manner, by immunosuppressive activity of IL-10. Therefore, IL-10 represents a very important "protective" factor for the developing gastric tumour.

\section{Acknowledgments}

This work was supported by the Polish Ministry of Science and Higher Education, Poland (Grant no. N401 018 $31 / 0338$ ), and partially by the University of Medical Sciences in Poznan, Poland (Grant no. 501-01-02206316-02658).

\section{References}

[1] F. Colucci, M. A. Caligiuri, and J. P. Di Santo, "What does it take to make a natural killer?" Nature Reviews Immunology, vol. 3, no. 5, pp. 413-425, 2003.

[2] M. J. Soloski, "Recognition of tumor cells by the innate immune system," Current Opinion in Immunology, vol. 13, no. 2, pp. 154-162, 2001.

[3] H. Takeuchi, Y. Maehara, E. Tokunaga, T. Koga, Y. Kakeji, and K. Sugimachi, "Prognostic significance of natural killer cell activity in patients with gastric carcinoma: a multivariate analysis," American Journal of Gastroenterology, vol. 96, no. 2, pp. 574-578, 2001.

[4] K. W. Moore, R. de Waal Malefyt, R. L. Coffman, and A. O'Garra, "Interleukin-10 and the interleukin-10 receptor," Annual Review of Immunology, vol. 19, pp. 683-765, 2001.

[5] J.-L. Mege, S. Meghari, A. Honstettre, C. Capo, and D. Raoult, "The two faces of interleukin 10 in human infectious diseases," The Lancet Infectious Diseases, vol. 6, no. 9, pp. 557-569, 2006.

[6] J. J. Letterio and A. B. Roberts, "Regulation of immune responses by TGF- $\beta$," Annual Review of Immunology, vol. 16, pp. 137-161, 1998.

[7] D. M. Kingsley, "The TGF- $\beta$ superfamily: new members, new receptors, and new genetic tests of function in different organisms," Genes and Development, vol. 8, no. 2, pp. 133-146, 1994.

[8] F. De Vita, M. Orditura, G. Galizia, et al., "Serum interleukin10 levels in patients with advanced gastrointestinal malignancies," Cancer, vol. 86, no. 10, pp. 1936-1943, 1999.

[9] M. Nakamura, M. Katano, A. Kuwahara, et al., “Transforming growth factor $\beta 1$ (TGF- $\beta 1$ ) is a preoperative prognostic indicator in advanced gastric carcinoma," British Journal of Cancer, vol. 78, no. 10, pp. 1373-1378, 1998.

[10] IARC Working Group, "Schistosomes, liver flukes and Helicobacter pylori: views and expert opinion of IARC working group on the evaluation of carcinogenic risks to humans," International Agency for Research on Cancer, vol. 61, pp. 177240, 1994. 
[11] T. Matysiak-Budnik and F. Mégraud, "Helicobacter pylori infection and gastric cancer," European Journal of Cancer, vol. 42, no. 6, pp. 708-716, 2006.

[12] N. Hafsi, P. Voland, S. Schwendy, et al., "Human dendritic cells respond to Helicobacter pylori, promoting NK cell and Th1effector responses in vitro," Journal of Immunology, vol. 173, no. 2, pp. 1249-1257, 2004.

[13] S. R. Hamilton and A. Aaltonen, Pathology and Genetics of Tumours of the Digestive System: Tumours of the Stomach, IARC Press, Lyon, France, 2000.

[14] Y. Yamaguchi, I. Takashima, M. Funakoshi, H. Kawami, and T. Toge, "Defective natural killer activity in gastric cancer patients: possible involvement of suppressor factor receptor," In Vivo, vol. 8, no. 3, pp. 279-284, 1994.

[15] C. Fortis, M. Foppoli, L. Gianotti, et al., "Increased interleukin-10 serum levels in patients with solid tumours," Cancer Letters, vol. 104, no. 1, pp. 1-5, 1996.

[16] G. Cai, R. A. Kastelein, and C. A. Hunter, "IL-10 enhances NK cell proliferation, cytotoxicity and production of IFN- $\gamma$ when combined with IL-18," European Journal of Immunology, vol. 29, no. 9, pp. 2658-2665, 1999.

[17] S. Mocellin, M. Panelli, E. Wang, et al., "IL-10 stimulatory effects on human NK cells explored by gene profile analysis," Genes and Immunity, vol. 5, no. 8, pp. 621-630, 2004.

[18] A. Taylor, J. Verhagen, K. Blaser, M. Akdis, and C. A. Akdis, "Mechanisms of immune suppression by interleukin-10 and transforming growth factor- $\beta$ : the role of T regulatory cells," Immunology, vol. 117, no. 4, pp. 433-442, 2006.

[19] Q. S. Wen, G. Z. Zhang, and X. T. Kong, "Modulation effect of cimetidine on the production of IL- 2 and interferon- $\gamma$ in patients with gastric cancer," Chinese Journal of Oncology, vol. 16, no. 4, pp. 299-301, 1994.

[20] C. A. J. Vosshenrich, S. I. Samson-Villéger, and J. P. Di Santo, "Distinguishing features of developing natural killer cells," Current Opinion in Immunology, vol. 17, no. 2, pp. 151-158, 2005.

[21] S. H. Chan, B. Perussia, J. W. Gupta, et al., "Induction of interferon $\gamma$ production by natural killer cell stimulatory factor: characterization of the responder cells and synergy with other inducers," Journal of Experimental Medicine, vol. 173, no. 4, pp. 869-879, 1991.

[22] D. Thong-Ngam, P. Tangkijvanich, R. Lerknimitr, V. Mahachai, A. Theamboonlers, and Y. Poovorawan, "Diagnostic role of serum interleukin-18 in gastric cancer patients," World Journal of Gastroenterology, vol. 12, no. 28, pp. 4473-4477, 2006.

[23] P. C. Konturek, J. Kania, J. W. Konturek, A. Nikiforuk, S. J. Konturek, and E. G. Hahn, "H. pylori infection, atrophic gastritis, cytokines, gastrin, COX-2, PPAR $\gamma$ and impaired apoptosis in gastric carcinogenesis," Medical Science Monitor, vol. 9, no. 7, pp. SR53-SR66, 2003.

[24] C.-F. Zambon, D. Basso, F. Navaglia, et al., "Pro- and antiinflammatory cytokines gene polymorphisms and Helicobacter pylori infection: interactions influence outcome," Cytokine, vol. 29, no. 4, pp. 141-152, 2005.

[25] E.M. El-Omar, C. S. Rabkin, M. D. Gammon, et al., "Increased risk of noncardia gastric cancer associated with proinflammatory cytokine gene polymorphisms," Gastroenterology, vol. 124, no. 5, pp. 1193-1201, 2003.

[26] C. H. Yun, A. Lundgren, J. Azem, et al., "Natural killer cells and Helicobacter pylori infection: bacterial antigens and interleukin-12 act synergistically to induce gamma interferon production," Infection and Immunity, vol. 73, no. 3, pp. 1482 1490, 2005.
[27] M. A. Cooper, T. A. Fehniger, and M. A. Caligiuri, "The biology of human natural killer-cell subsets," Trends in Immunology, vol. 22, no. 11, pp. 633-640, 2001.

[28] R. Jacobs, G. Hintzen, A. Kemper, et al., "CD56 bright cells differ in their KIR repertoire and cytotoxic features from CD56 dim NK cells," European Journal of Immunology, vol. 31, no. 10, pp. 3121-3126, 2001.

[29] Z. Ren, G. Pang, R. Clancy, et al., "Gastric carcinoma: T-cell response and vascularity. Shift of the gastric T-cell response in gastric carcinoma," Journal of Gastroenterology and Hepatology, vol. 16, no. 2, pp. 142-148, 2001.

[30] K. Vagenas, C. Spyropoulos, V. Gavala, and A. C. Tsamandas, "TGF $\beta 1, T G F \beta 2$, and TGF $\beta 3$ protein expression in gastric carcinomas: correlation with prognostics factors and patient survival," Journal of Surgical Research, vol. 139, no. 2, pp. 182188, 2007.

[31] P.-E. Gleizes, J. S. Munger, I. Nunes, et al., "TGF- $\beta$ latency: biological significance and mechanisms of activation," Stem Cells, vol. 15, no. 3, pp. 190-197, 1997.

[32] L. M. Wakefield, J. J. Letterio, T. Chen, et al., “Transforming growth factor- $\beta 1$ circulates in normal human plasma and is unchanged in advanced metastatic breast cancer," Clinical Cancer Research, vol. 1, no. 1, pp. 129-136, 1995. 


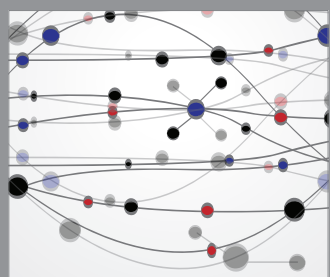

The Scientific World Journal
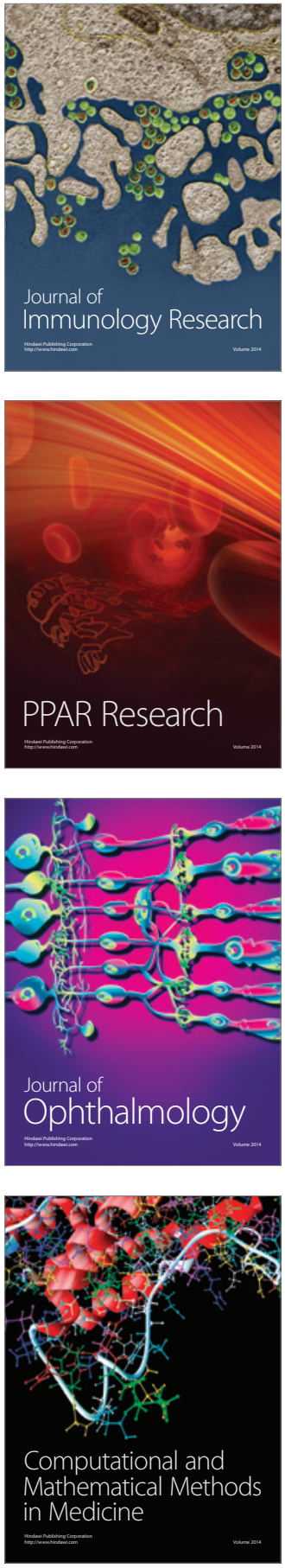

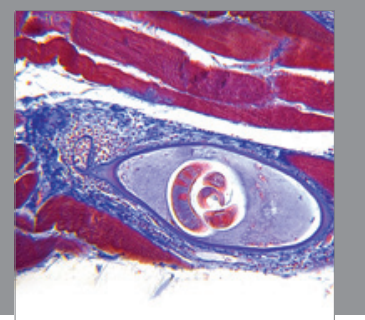

Gastroenterology

Research and Practice
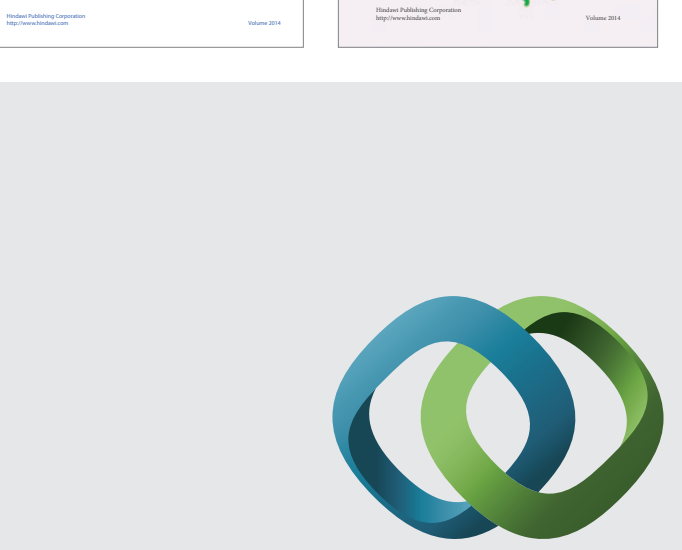

\section{Hindawi}

Submit your manuscripts at

http://www.hindawi.com
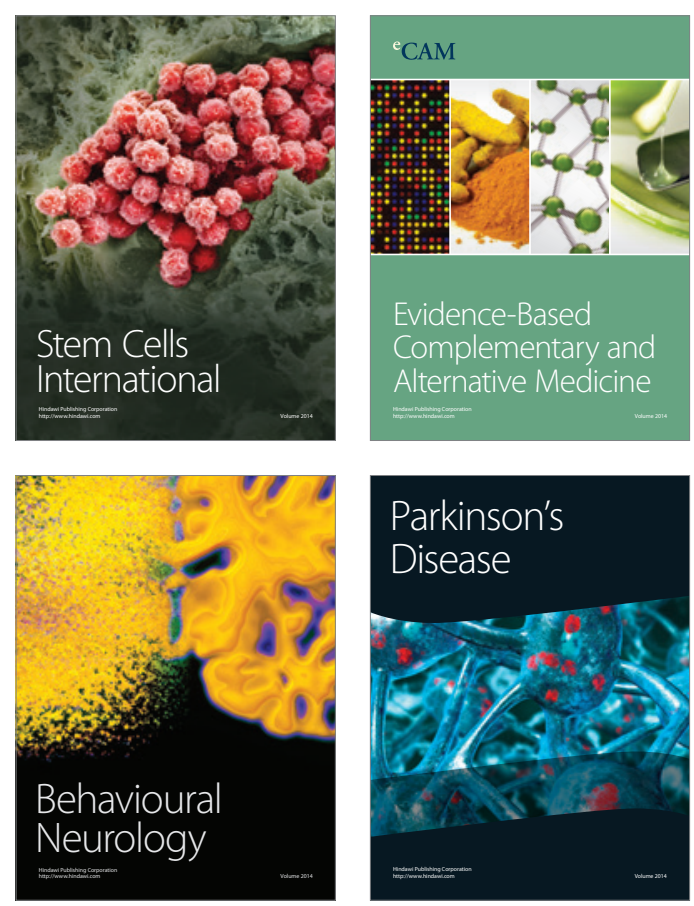

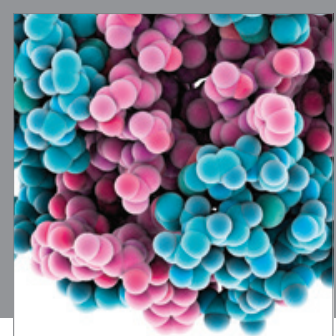

Journal of
Diabetes Research

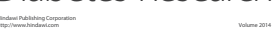

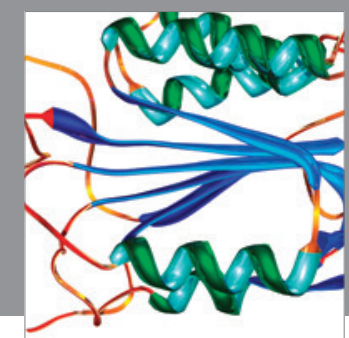

Disease Markers
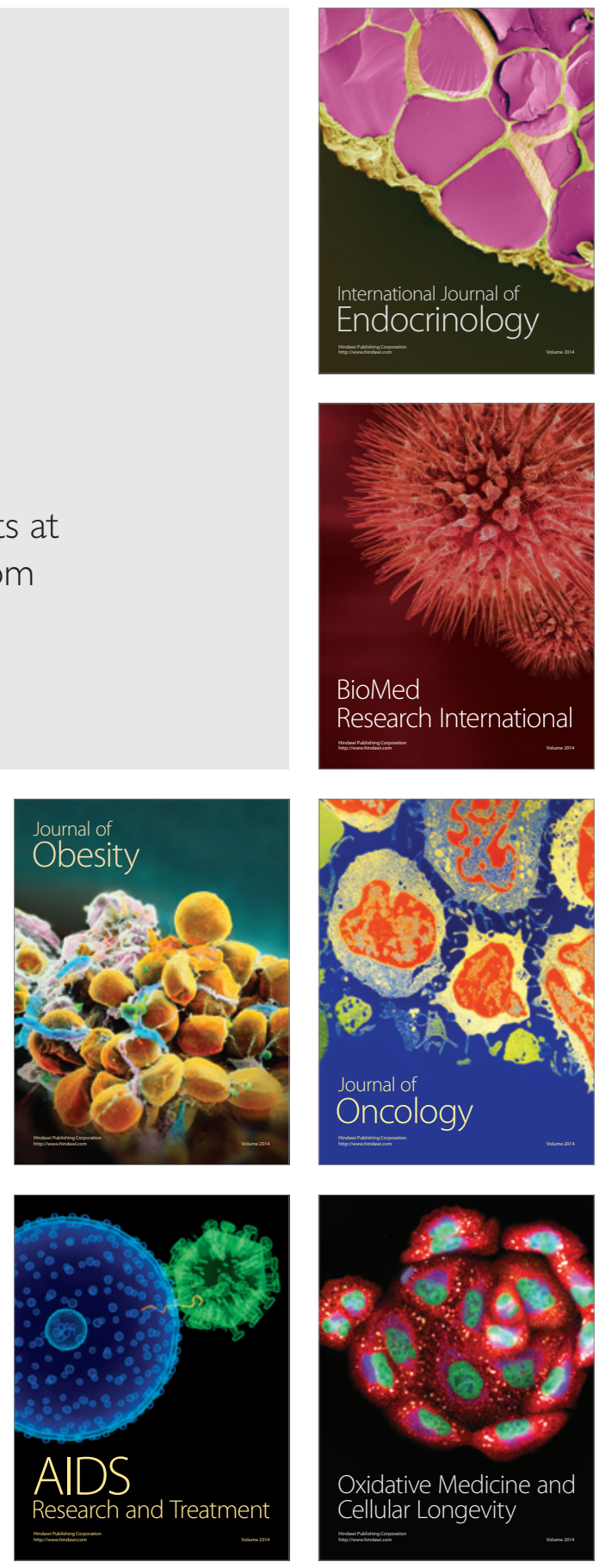